\title{
Thrombectomy vs. Systemic Thrombolysis in Acute Embolic Stroke with High Clot Burden: A Retrospective Analysis
}

\section{Thrombektomie vs. systemische Thrombolyse beim akuten embolischen Schlaganfall mit hoher Thrombuslast: Eine retrospektive Analyse}

Authors

Affiliations
J. K. Meyne' ${ }^{1}$, P. R. Zimmermann ${ }^{1}$, A. Rohr ${ }^{2}$, C. Riedel ${ }^{2}$, H. C. Hansen ${ }^{3}$, U. Pulkowski ${ }^{4}$, A. Thie ${ }^{5}$, T. Holst ${ }^{6}$, F. Papengut ${ }^{1}$, R. Stingele ${ }^{7}$, K. Schepelmann $^{8}$, O. Jansen ${ }^{2}$, G. Deuschl' ${ }^{1}$, A. Binder ${ }^{1}$

Affiliation addresses are listed at the end of the article.
Key words

- stroke

thrombectomy

- thrombolysis

stent retriever

received 23.12.2014

accepted 13.1.2015

\section{Bibliography}

Dol http://dx.doi.org/ 10.1055/s-0034-1399222

Published online: 1.4.2015

Fortschr Röntgenstr 2015; 187:

555-560 @ Georg Thieme

Verlag KG Stuttgart · New York . ISSN 1438-9029

\section{Correspondence}

Dr. Johannes Konrad Meyne Neurology, University Hospital Schleswig-Holstein

Arnold-Heller-Str. 3

Campus Kiel

24105 Kiel

Germany

Tel.: +49/431/5978550

Fax: $+49 / 431 / 5978502$

j.meyne@neurologie.uni-kiel.de

\section{Zusammenfassung \\ $\nabla$}

Ziel: Der Nutzen einer i. v.-Thrombolyse bei akutem ischämischem Schlaganfall mit hoher Thrombuslast ist begrenzt. Eine erfolgreiche Rekanalisation durch die i.v.-Thrombolyse wird äußerst unwahrscheinlich, wenn die Thrombuslänge $7 \mathrm{~mm}$ übersteigt. Die vorliegende retrospektive Studie soll daher den Nutzen und die Sicherheit der Neurothrombektomie mittels des Trevo $^{\circledR}$ Stentretrievers in der Behandlung des akuten embolischen Schlaganfalles an Patienten mit einer Thrombuslänge von $\geq 8 \mathrm{~mm}$ prüfen.

Material und Methoden: 40 Patienten mit einem akuten Verschluss eines vorderen intrakraniellen Hirngefäßes und einer Thrombuslänge von $\geq 8 \mathrm{~mm}$ wurden mittels Neurothrombektomie behandelt. Es wurde das klinische Ergebnis mit einer historischen Kontrollgruppe aus 42 Patienten mit einer Thrombuslänge von ebenfalls $\geq 8 \mathrm{~mm}$ verglichen, welche nur mit einer i.v.-Thrombolyse behandelt wurden. In beiden Gruppen wurde das klinische Ergebnis anhand der modifizierten Rankin-Skala (mRS) bei Entlassung und nach 90 Tagen bestimmt.

Ergebnisse: Die Patienten unterschieden sich nicht bezüglich Alter, mRS bei Aufnahme, Thrombuslänge oder der Zeit vom Symptombeginn bis Beginn der i.v.-Thrombolyse, jedoch wies die Thrombektomie-Gruppe einen höheren NIHSS bei Aufnahme auf. Eine erfolgreiche Rekanalisation wurde in 33/ 40 Patienten (83\%) mit der Neurothrombektomie erreicht. 15 Patienten erhielten eine i.v.-Thrombolyse vor der Neurothrombektomie. Der mediane mRS bei Entlassung betrug 3,5 (1,25-5) vs. 5 (46; $\mathrm{p}<0,01)$ und an Tag $903(1-4)$ vs. $5(4-6$; $\mathrm{p}<0,01$ ). Symptomatische intrakranielle Blutungen traten in 3 vs. 7 Patienten auf, 3 vs. 17 Patienten starben innerhalb von 90 Tagen (je Thrombektomie vs. Kontrolle). Es ereigneten sich nur wenig Interventions-bezogene Komplikationen.

\section{Abstract \\ $\nabla$}

Purpose: The efficacy of i.v. thrombolysis in acute stroke with high clot burden is limited. Successful recanalization is very unlikely if the thrombus length exceeds $7 \mathrm{~mm}$. Thus this retrospective controlled study evaluated the efficacy and safety of neurothrombectomy in the treatment of acute embolic stroke in patients selected by a thrombus length of $\geq 8 \mathrm{~mm}$ using the stent retriever Trevo ${ }^{\circledR}$ device.

Materials and Methods: 40 patients with acute occlusion of the anterior intracranial arteries with a thrombus length of $\geq 8 \mathrm{~mm}$ were treated with neurothrombectomy. We compared the outcome with a historical cohort of 42 patients with a thrombus length of $\geq 8 \mathrm{~mm}$ that received i. v. thrombolysis only. Clinical outcome was assessed by modified Rankin scale in both groups at discharge and on day 90 .

Results: Patients did not differ in age, mRS on admission, thrombus length or time from symptom onset to i.v. thrombolysis, but the thrombectomy group had higher NIHSS on admission. Successful recanalization was achieved in 33/40 patients (83\%) with neurothrombectomy. 15 patients received i. v. thrombolysis prior to neurothrombectomy. Median mRS at discharge was $3.5(1.25-5)$ vs. $5(4-6 ; \mathrm{p}<0.01)$ and on day $903(1-4)$ vs. 5 $(4-6 ; p<0.01)$. Symptomatic hemorrhage occurred in 3 vs. 7 patients. 3 vs. 17 patients died within 90 days (thrombectomy vs. control each). There were only a few intervention-related complications.

Conclusion: Thrombectomy in acute stroke with high clot burden using the Trevo ${ }^{\circledR}$ device has a low risk and improved clinical outcome compared to i. v. thrombolysis alone. Treatment selection by a clot length of $\geq 8 \mathrm{~mm}$ might be a powerful approach to improve the outcome of mechanical thrombectomy. 
Schlussfolgerung: Eine Thrombektomie mit dem Trevo ${ }^{\circledR}$-Device bei akutem Schlaganfall mit hoher Thrombuslast hat ein geringes Risiko und verbessert das klinische Ergebnis im Vergleich zur alleinigen Thrombolyse. Eine Indikationsstellung zur Thrombektomie anhand einer Thormbuslänge von $\geq 8 \mathrm{~mm}$ könnte das Behandlungsergebnis nach Thrombektomie verbessern.

Kernaussagen:

- Eine Thrombuslänge von $\geq 8 \mathrm{~mm}$ könnte ein nützliches Kriterium zur Indikationsstellung einer Neurothrombektomie darstellen.

- Eine alleinige Thrombolyse führt bei hoher Thrombuslast zu einem schlechten klinischen Ergebnis.

- Die Thrombektomie unter Verwendung des Trevo ${ }^{\circledR}$-Stentretriever scheint sicher und effizient.

\section{Purpose}

The effect of i.v. thrombolysis seems to be limited in patients with a higher clot burden [1]. Mechanical thrombectomy and large vessel recanalization using stent-based devices are increasingly used for the treatment of patients with acute embolic stroke. Stent retrievers can achieve fast recanalization even with large thrombi. Thus it is conceivable that patients with small thrombi can be treated efficiently with systemic thrombolysis whereas a high clot burden requires thrombectomy. Non-contrast thin-slice CT is able to detect thrombus location and size in patients with acute intracranial vessel occlusion sufficiently [2] and is readily available in the routine clinical diagnostic workup of acute stroke patients.

We retrospectively compared the clinical outcome in patients, who received thrombolytic therapy only with patients who underwent neurothrombectomy with or without additional thrombolysis. Patients in both groups had an acute anterior circulation occlusion and a thrombus length of at least $8 \mathrm{~mm}$. This thrombus length has been recently proposed as the threshold for treatment allocation to systemic thrombolysis or neurothrombectomy because of a probability below $1 \%$ for successful recanalization by i. v. thrombolysis with thrombi above this size [1]. The aim of the study was to test if neurothrombectomy with the Trevo ${ }^{\circledR}$ device is beneficial compared to standard stroke treatment in high clot burden stroke with a thrombus length of $\geq 8 \mathrm{~mm}$.

\section{Methods \\ $\nabla$}

\section{Patient selection}

The predefined selection criteria for the retrospective inclusion of patients with intraarterial thrombectomy were: Occlusion of a large vessel within the anterior circulation by a thrombus with a length of $\geq 8 \mathrm{~mm}$, NIHSS $\geq 4$, age of $\geq 18$ and $\leq 85$. Thrombectomy had to be started within 8 hours after symptom onset. Patients were excluded if they had had a previous stroke within 30 days, seizure at the onset of stroke, signs of intracranial hemorrhage, aneurysm or early ischemic changes larger than one third of the middle cerebral artery territory.

40 consecutive patients (median age 71 , range $20-83 ; 27$ females) fulfilling the inclusion criteria were treated with neurothrombectomy using the Trevo ${ }^{\circledR}$ device in addition to standard stroke treatment between January 2011 and March 2012 and were included in the study group ( $\bullet$ Table 1 ). The median National Institutes of Health Stroke Scale (NIHSS) on admission was
Key Points:

- Clot length of $\geq 8 \mathrm{~mm}$ might be a valuable criterion for indicating neurothrombectomy.

- Thrombolysis only in high clot burden is associated with poor clinical outcome.

- Thrombectomy using the Trevo ${ }^{\circledR}$ stent retriever is safe and effective.

Citation Format:

- Meyne JK, Zimmermann PR, Rohr A. etal. Thrombectomy vs. Systemic Thrombolysis in Acute Embolic Stroke with High Clot Burden: A Retrospective Analysis. Fortschr Röntgenstr 2015; 187: $555-560$

$14(12-20)$. The duration of symptoms on admission was 148 min (58-268). We compared to 42 patients (median age 72.5 , range $35-86 ; 21$ females) of a historical control group with a thrombus length of $\geq 8 \mathrm{~mm}$ that received i. v. thrombolysis only between July 2007 and January 2009 ( Table 1). During this period neurothrombectomy was not implemented in our clinical routine. The National Institutes of Health Stroke Scale (NIHSS) on admission was $13(10-16)$, and the duration of symptoms was $70 \mathrm{~min}(55-90)$. The clinical data after 90 days was accessible through a local stroke registry.

\section{Imaging and thrombus length measurement}

In order to access clot burden, the length of the hyperdense arterial segment was measured on multiplanar reformatted thick-slab maximum intensity projections of $0.625 \mathrm{~mm}$ thin NECT slices [1] aligned with the thrombus axis. All images were obtained using a

Table 1 Patient characteristics at baseline.

Tab. 1 Patientencharakteristika vor Behandlungsbeginn.

\begin{tabular}{|c|c|c|c|}
\hline characteristics & $\begin{array}{l}\text { neurothromb- } \\
\text { ectomy }\end{array}$ & $\begin{array}{l}\text { thrombolysis } \\
\text { only }\end{array}$ & p-value \\
\hline number of patients, $n$ & 40 & 42 & \\
\hline \multicolumn{4}{|l|}{ demographic data } \\
\hline $\begin{array}{l}\text { - sex, n, male:female } \\
\text { (\%) }\end{array}$ & $\begin{array}{l}13: 27 \\
(33 \text { vs. } 68 \%)\end{array}$ & $\begin{array}{l}21: 21 \\
(50 \text { vs. } 50 \%)\end{array}$ & \\
\hline - age, $y^{1}$ & $71(54-76)$ & $72.5(66-80)$ & 0.15 \\
\hline \multicolumn{4}{|c|}{ clinical deficit before treatment } \\
\hline$-\mathrm{mRS}^{1}$ & $5(4-5)$ & $5(4-5)$ & 0.21 \\
\hline - NIHSS ${ }^{1}$ & $14(12-20)$ & $13(10-16)$ & 0.05 \\
\hline \multicolumn{4}{|l|}{ site of occlusion } \\
\hline - right/left, n & $16 / 24$ & $20 / 22$ & \\
\hline- ICA-T, n & 13 & 10 & \\
\hline - MCA-M1, n & 26 & 30 & \\
\hline - MCA-M2, n & 1 & 2 & \\
\hline thrombus length ${ }^{1}, \mathrm{~mm}$ & $13(10-20)$ & $12.4(9-17)$ & 0.22 \\
\hline \multicolumn{4}{|l|}{ i.v. thrombolysis } \\
\hline - rtPA, n & $15(37.5 \%)$ & $42(100 \%)$ & \\
\hline $\begin{array}{l}\text { - time from symptom on- } \\
\text { set to IVT, min }\end{array}$ & $118(98-151)$ & $133(104-166)$ & 0.89 \\
\hline $\begin{array}{l}\text { - time from symptom } \\
\text { onset to admission } \\
\text { at our site }{ }^{1}, \text { min }\end{array}$ & $148(58-259)$ & $70(55-90)$ & $<0.01$ \\
\hline
\end{tabular}

M1 / M2, M1 / M2 segment of middle cerebral artery; ICA-T carotid T; IVT i. v. thrombolysis. Time from onset to i. v. treatment: Patients were allocated from external hospitals and partially received i. v. thrombolysis before admission at our site.

${ }^{1}$ Data are presented as median (interquartile range). 
64-detector row CT scanner (Brilliance 64; Philips, Best, The Netherlands) with a tube voltage of $120 \mathrm{kV}$ and a tube current of 320 mAs, an incremental scanning mode and a smooth reconstruction kernel. Measurements were done by an experienced neuroradiologist blinded to the patient data using the EMPR $3 \mathrm{D}$ plugin postprocessing capability of the IMPAX ${ }^{\circledR}$ EE PACS workstation (AGFA ${ }^{\circledR}$ Health Care N.V., Mortsel, Belgium). With this plugin, a $3 \mathrm{D}$ curved line was drawn along the HMCAS for measurement of the thrombus length in each patient. Occlusion of the artery was then verified by contrast-enhanced CT angiography.

\section{Acute stroke management}

Patients eligible for $\mathrm{i}$. v. thrombolysis ( $\mathrm{n}=15$ in the thrombectomy group, all in the control group) were treated with intravenous rtPA $\left(0.9 \mathrm{mg} / \mathrm{kg}\right.$, max. 90mg; Actilyse ${ }^{\circledR}$; Boehringer Ingelheim, Germany) within 4.5 hours after symptom onset according to the European guidelines for stroke treatment [3]. Patients eligible for thrombectomy were treated using a bridging concept with i.v. thrombolysis followed by the angiographic procedure which was initiated within 8 hours after symptom onset. 25 patients were treated exclusively with mechanical thrombectomy. Intravenous GP2b3a antagonists were given in 4 patients due to additional stenting of internal carotid artery stenosis and due to stenting of an MCA stenosis in one case.

\section{Mechanical thrombectomy}

Prior to mechanical thrombectomy, patients were evaluated by non-contrast-enhanced incremental CCT as described above followed by $\mathrm{CT}$ perfusion and $\mathrm{CT}$ angiography. All patients received general anesthesia. A flexible 6F sheath (Super Arrow-Flex ${ }^{\circledR}$; Arrow International, Inc.; Reading, PA, USA) was placed into the proximal internal carotid artery via a transfemoral approach. In all patients, a distal guiding/aspiration catheter (either $D C^{\circledR}$ 057, iDAC ${ }^{\circledR} 070$ (Concentric Medical, Inc.; Mountain View, CA, USA) or ReFlex ${ }^{\circledR} A+058$ (Reverse Medical Corporation; Irvine, CA, USA)) was used for clot aspiration. Using a 2.7F 0.021" microcatheter (Trevo ${ }^{\circledR}$ Pro 18; Concentric Medical Inc.; Mountain View, CA, USA), the Trevo ${ }^{\circledR}$ stent retriever was released penetrating the thrombus and was left there for three to five minutes. Clot retrieval was combined with aspiration through a $20 \mathrm{ccm}$ syringe. The procedure was repeated when necessary and the TICI score was recorded prior to and after thrombectomy.

\section{Treatment evaluation}

Successful vessel recanalization by thrombectomy was defined by a recanalization rate of TICI 2 b or 3 confirmed by angiography. The clinical status was scored using the NIHSS and modified Rankin Scale (mRS) on admission, mRS at discharge from hospital, and on day 90. The latter was accessible through a regional prospective stroke registry, in which the data was acquired by a questionnaire. Control CT scans were used to determine infarct location and occurrence of hemorrhage. A symptomatic hemorrhage was defined as intracranial bleeding with a neurological deterioration of $\geq 4$ points in NIHSS.

\section{Statistics}

Data are presented as median and interquartile range. For group data comparison the Mann-Whitney U-test was used. P-values $<0.05$ were regarded as statistically significant. Pearson correlation was used to assess correlations between time to revascularization and clinical outcome (mRS). $\mathrm{x}^{2}$-test was used to assess significant differences in frequencies.

\section{Results}

\section{$\nabla$}

Demographic and clinical baseline data

The demographic and clinical data are shown in 0 Table 1. Groups (thrombectomy vs. i.v. thrombolysis) differed in NIH-SS on admission (14 [12-20] vs. 13 [10-16]; p=0.05), but did not differ in age, mRS on admission ( $\bullet$ Fig. 1 ) and thrombus length. The groups differed significantly in the time from symptom onset until the time of admission (148 min [58 - 259] vs. 70 min [5590]; $p=0.001$ ), because some patients for thrombectomy were referred from other hospitals. There was no difference concerning the time from symptom onset to i.v. thrombolytic therapy (118 min (98-151) vs. $133 \mathrm{~min}(104-166))$.

\section{Angiographic outcome and safety}

The mean duration from admission to the start of angiographic interventions was $101 \mathrm{~min}(81-144)$. Successful recanalization was achieved in 33 patients ( $83 \%$ ). The time from symptom onset to recanalization was $309 \mathrm{~min}(248$ - 395) ( Table 2$)$. The following procedure-related complications occurred: In one patient with M1 occlusion receiving i. v. thrombolysis prior to mechanical recanalization, a symptomatic intracranial hemorrhage occurred within 24 hours. The patient reached good recovery (mRS 2) after 90 days. In another patient embolization of the initially unaffected anterior cerebral artery occurred during successful recanalization of an M1 occlusion. In one patient the advancing microcatheter perforated the target vessel distal to an M1 thrombus. The procedure was terminated and the patient remained asymptomatic for the resulting subarachnoid hemorrhage.

\section{Clinical outcome}

The median mRS at discharge was significantly better in the thrombectomy group compared to the control group (3.5 [1.255] vs. 5 [4-6], p < 0.001) and remained better on day 90 (3 [1 - 4] vs. 5 [4-6], p <0.001) ( $\bullet$ Table 3, $\bullet$ Fig. 2, 3). There was no improvement of mRS from admission to discharge in $7(18 \%)$ thrombectomy patients and $24(57 \%)$ patients of the control group ( $\mathrm{p}<0.01$ ). On day 90,17 of the 40 patients ( $43 \%$ ) having been treated with thrombectomy presented a slight disability $(\mathrm{mRS} \leq 2)$, but only 2 of the 42 patients (5\%) in the control group. The time to revascularization did not correlate with the

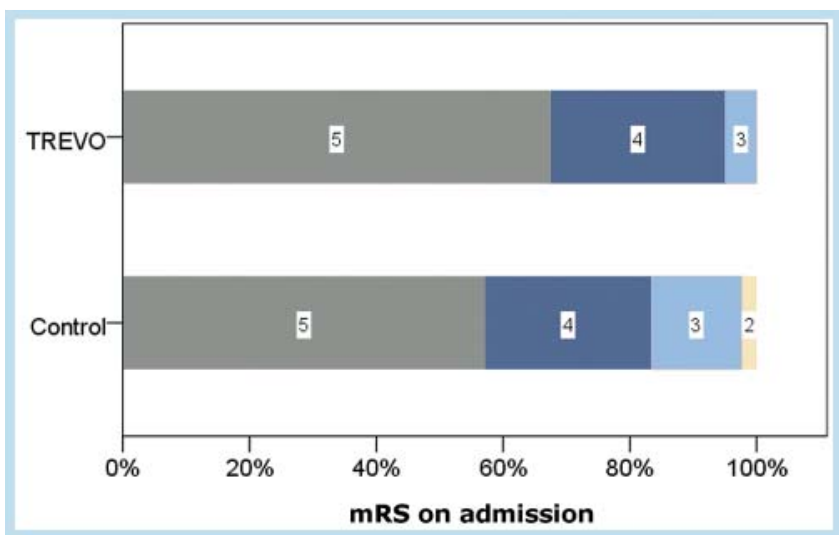

Fig. 1 MRS on admission in the thrombectomy (Trevo) and control group (Control).

Abb. 1 MRS bei Aufnahme in der Thrombektomie- (Trevo) und Kontrollgruppe (Control). 
Table 2 Interventional data.

Tab. 2 Daten zur interventionellen Therapie.

\begin{tabular}{|c|c|c|}
\hline characteristics & $\begin{array}{l}\text { neurothromb- } \\
\text { ectomy }\end{array}$ & $\begin{array}{l}\text { thrombolysis } \\
\text { only }\end{array}$ \\
\hline recanalization & 1 & 2 \\
\hline $\begin{array}{l}\text { - successful recanalization } \\
\text { ( } \mathrm{TICI} 2 \mathrm{~b} ; 3), \mathrm{n}(\%)\end{array}$ & $33(83 \%)$ & $0(0 \%)$ \\
\hline$-\mathrm{TICl} 3, \mathrm{n}$ & 20 & n.a. \\
\hline$-\mathrm{TICl} 2 \mathrm{~b}, \mathrm{n}$ & 13 & n. a. \\
\hline - partial recanalization ( $\mathrm{TICI} 2 \mathrm{a}), \mathrm{n}$ & 4 & n. a. \\
\hline - recanalization failure ( $\mathrm{TICI} 0-1), \mathrm{n}$ & 3 & n. a. \\
\hline \multicolumn{3}{|l|}{ duration to recanalization } \\
\hline $\begin{array}{l}\text { - time from admission to first series }{ }^{3} \text {, } \\
\text { min }\end{array}$ & $101(81-144)$ & n. a. \\
\hline - total time to recanalization ${ }^{3}$, min & $309(248-395)$ & n. a. \\
\hline - duration procedure ${ }^{3}$, min & $61(50-103)$ & n. a. \\
\hline \multicolumn{3}{|l|}{ stenting } \\
\hline ICA, n & 6 & n. a. \\
\hline MCA, $n$ & 1 & n. a. \\
\hline
\end{tabular}

n. a.: not applicable.

${ }^{1}$ Controlled during intervention;

${ }^{2}$ Controlled with CT or TCD 24 hrs after i. v. rTPA.

${ }^{3}$ Data are presented as median (interquartile range);

Table 3 Clinical outcome and safety data.

Tab. 3 Klinisches Ergebnis und Sicherheitsdaten.

\begin{tabular}{|llll|}
\hline characteristics & $\begin{array}{l}\text { neurothrom- } \\
\text { bectomy }\end{array}$ & $\begin{array}{l}\text { thrombo- } \\
\text { lysis only }\end{array}$ & p-value \\
\hline mRS at discharge $^{1}$ & $3.5(1.25-5)$ & $5(4-6)$ & $<0.01$ \\
\hline${\text { mRS after } 90 \text { days }^{1}}^{\text {mRS } \leq 2 \text { at } 90 \text { days, }^{n}(\%)}$ & $3(1-4)$ & $5(4-6)$ & $<0.001$ \\
\hline death in hospital, $\mathrm{n}(\%)$ & $17(43 \%)$ & $2(5 \%)$ & $<0.001$ \\
\hline death in 90 days, $\mathrm{n}(\%)$ & $3(8 \%)$ & $11(26 \%)$ & $<0.02$ \\
\hline no clinical improvement, $\mathrm{n}(\%)$ & $7(18 \%)$ & $17(41 \%)$ & $<0.02$ \\
\hline symptomatic ICH, $\mathrm{n}(\%)$ & $3(8 \%)$ & $24(57 \%)$ & $<0.01$ \\
\hline non-symptomatic SAH, $\mathrm{n}(\%)$ & $4(10 \%)$ & $7(17 \%)$ & 0.21 \\
\hline
\end{tabular}

${ }^{1}$ Data are presented as median (interquartile range)

clinical improvement assessed with the mRS $(r=-1.9 ; p=0.1)$. After thrombectomy three patients died within 90 days ( $8 \%$ ), while 17 patients $(41 \%)$ died in the control group. Symptomatic intracerebral hemorrhage occurred in 3 ( $8 \%$ ) vs. 7 (17\%) patients. 4 vs. 0 patients showed mild non-symptomatic subarachnoid hemorrhage $(p<0.05)$. In the thrombectomy group 3 patients with hemorrhage and 1 patient with subarachnoidal hemorrhage received thrombolytic therapy within the bridging regime.

\section{Discussion}

$\nabla$

In this study we compared mechanical neurothrombectomy in patients with a high clot burden to a control group treated with i. v. rtPA thrombolysis alone. Clot burden is a major factor for clinical outcome in acute embolic stroke [4] and accordingly thrombus length is a main factor for recanalization after i. v. thrombolysis [1]. Assessment of thrombus length is easily implemented in routine stroke CT scanning without relevant further time consumption. Furthermore, the success of recanalization is a critical factor for clinical outcome after acute embolic stroke. In patients

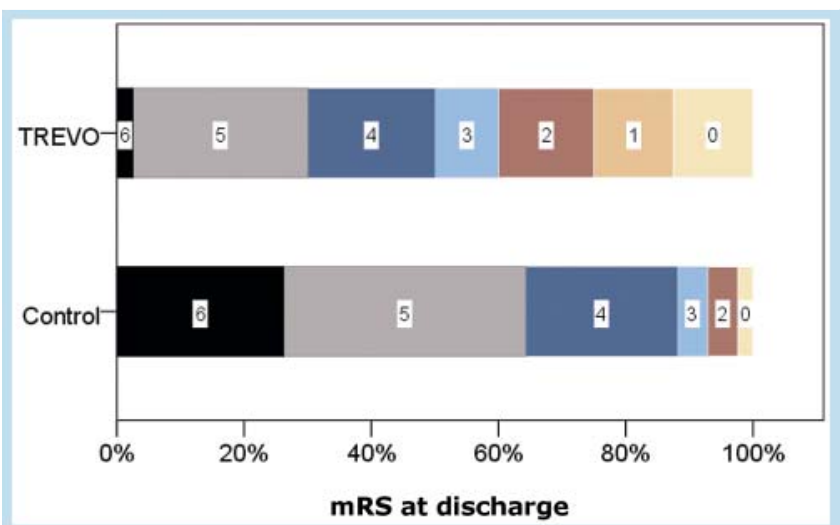

Fig. 2 Clinical outcome (mRS) at discharge in the thrombectomy (Trevo) and control group (Control).

Abb. 2 Klinisches Ergebnis (mRS) bei Entlassung in der Thrombektomie(Trevo) und Kontrollgruppe (Control).

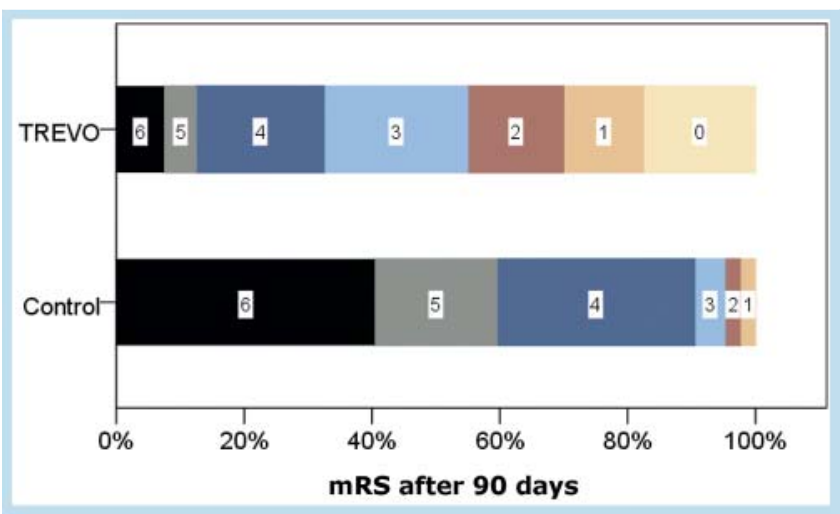

Fig. 3 Clinical outcome (mRS) 90 days after stroke in the thrombectomy (Trevo) and control group (Control).

Abb. 3 Klinisches Ergebnis (mRS) 90 Tage nach Schlaganfall in der Thrombektomie- (Trevo) und Kontrollgruppe (Control).

with a thrombus length of more than $8 \mathrm{~mm}$, i. v. thrombolysis achieved recanalization in less than $1 \%$ [1] and usually results in a poor clinical outcome. Accordingly, only $5 \%$ of the patients in our control group reached the favorable outcome of $\mathrm{mRS} \leq 2$. In this study we found a much better outcome of the mechanical thrombectomy group with regard to survival and disability at 90 days and an acceptable risk profile of the intervention.

Our data show that mechanical thrombectomy using the Trevo ${ }^{\circledR}$ device in acute stroke of the anterior circulation is highly effective. The intervention using the Trevo ${ }^{\circledR}$ device showed a remarkably high rate of successful recanalization (TICI 2 b or 3 ) in $83 \%$. This exceeds the recanalization rates of the Merci trials (69.5\%, TIMI II-III) [5], (44\%)[6], the IMS-III trial (41\%)[7], the MR RESCUE trial (27\%)[8] and the recently published MR CLEAN trial (58.7\%)[9], which was the first positive RCT on intraarterial treatment against standard stroke treatment. Comparable results have been published by other retrospective trials using the Penumbra system (81.6\%, TIMI II-III) [10], the Solitaire device $(90 \%, 79 \%)[11,12]$, the Revive ${ }^{\circledR}$ device $(100 \%, n=10)$ [13], the Trevo $^{\circledR}$ device $(68 \%, 39 \%, 78.3 \%)$ in three trials $[6,14,15]$ and using the Trevo $^{\circledR}$ or Solitaire ${ }^{\circledR}$ device $(83.9 \%$, TICI 2 a or 3$)$ in the 
case of Pagola et al. [16]. Thus, there is good evidence that mechanical thrombectomy using stent retrievers achieves high rates of successful recanalization. However, none of these previous studies assessed thrombus length.

The clinical outcome was also favorable after thrombectomy. $43 \%$ of the patients lead an independent life ( $\mathrm{mRS} \leq 2)$ compared to $5 \%$ in the control group despite the more severe stroke on admission in the thrombectomy group. In our study mortality seems to be reduced by thrombectomy as well, as indicated by a decrease from $41 \%$ to $8 \%$. Previous studies compared intraarterial thrombectomy to standard stroke treatment in acute stroke patients. Three randomized controlled trials failed to show clinical benefit by intraarterial treatment $[7,8,17]$. The inclusion criteria are discussed as a reason for this failure, but the main factor seems to be the low recanalization rate of $27 \%$ to $41 \%$ in the IMS-III and MR RESCUE trial. This may be due to the infrequent use of stent retrievers or the usage of old recanalization devices in these studies. For example, in the IMS-III trial, only 4 patients were treated with stent retriever devices. Furthermore, in the SYNTHESIS trial and IMS-III trial, no demonstration of large artery occlusion was required. Therefore, the cohorts of these studies are not comparable to the patients analyzed in our study. The randomized controlled MR CLEAN trial [9] very recently proved a clinical benefit of intraarterial treatment compared to standard stroke treatment. Occlusion of the distal internal carotid artery, the middle cerebral artery (M1, M2) or anterior cerebral artery (A1, A2) was required for inclusion and thrombectomy was carried out using a stent retriever in $81.5 \%$ of the cases. Thus, the findings of the MR CLEAN trial are in accordance with the results of our study, but thrombus length was not assessed in that trial. However, the clinical and procedural outcome in our study even exceeds the results of the MR CLEAN trial and, in contrast, significant reduction of mortality could be observed in our study. Thus, patient identification by thrombus length, not only the site of occlusion, and solely the use of highly effective stent retrievers seem to be important corner points for successful intraarterial treatment. Once more, registry studies in acute stroke using stent-based thrombectomy also revealed an increase in favorable outcome after 90 days: Leker et al. found up to $60 \%$ of patients treated by thrombectomy reaching an mRS of 0 to 2 compared to $37.5 \%$ in patients treated by i. v. thrombolysis [18]. In a recent study a 90day favorable outcome of even $77 \%$ and a recanalization rate of $90 \%$ could be achieved using the Solitaire ${ }^{\circledR}$ device [19]. Thus, the application of different thrombectomy devices may be the reason for the controversial findings since stent retriever devices showed higher recanalization rates and higher clinical improvement in comparison with other devices [6, 11, 14, 19-23]. We conclude that the significantly higher rate of favorable outcome in patients treated with neurothrombectomy in comparison to patients treated with i.v. thrombolysis alone is caused both by the usage of a stent retriever device for mechanical thrombectomy and patient selection based on the criterion of thrombus length. This might be a very robust criterion indicating neurothrombectomy rather than site of occlusion only.

We had three serious complications among 40 patients which finally led to death in one, poor outcome in another and a favorable outcome in another. We consider this an acceptable risk because of the high mortality in this cohort of stroke patients. However, the complication rate was even lower in the neurothrombectomy group compared to i.v. thrombolysis only. In addition, the incidence of symptomatic intracranial hemorrhages after thrombectomy is not higher than with systemic thrombolysis alone. A higher rate of non-symptomatic subarachnoid hemorrhages in the thrombectomy group might be consistent with reperfusion injury after large vessel recanalization. However, the complication rate seems to be lower than with other thrombectomy devices but head-to-head studies are needed. Furthermore, the four randomized controlled trials $[7-9,17]$ on intraarterial treatment found no increase in severe adverse events even though three of them did not show superiority of intraarterial treatment. Thus, mechanical thrombectomy seems to be safe in patients with and without previous intravenous thrombolysis.

\section{Conclusion}

Patient selection for neurothrombectomy by thrombus length in acute stroke patients and implementation of stent retriever devices for neurothrombectomy provided a clinically highly effective and technically safe method for successful recanalization with an acceptable risk while patients with a comparable clot burden treated with i.v. thrombolysis only had a low probability of reaching a favorable clinical outcome and showed a high rate of mortality. Our study had an even better result than the MR CLEAN study but it was retrospective and open.

Nevertheless, a clot length of at least $8 \mathrm{~mm}$ seems to be an additional valuable criterion for indicating neurothrombectomy in acute stroke patients and our results may guide future randomized controlled trials with comparison of neurothrombectomy with systemic thrombolysis only in patients with a thrombus length of more than $7 \mathrm{~mm}$, since recently published controlled trails have not implemented such a criterion. However, further controlled clinical trials on clinical efficacy and safety are warranted and, like the THERAPY trial [NCT01 429350], are on the way.

\section{Clinical relevance of the study}

- Increasing evidence supports neurothrombectomy in addition to standard stroke treatment in acute embolic stroke.

- Patients with severe acute stroke syndromes should be carefully evaluated regarding high clot burden and should be considered for neurothrombectomy.

- Not only site of occlusion but also thrombus length should be taken into account when thrombectomy is considered.

Thrombectomy in patients with a high clot burden using the Trevo ${ }^{\circledR}$ stent retriever seems to be safe and effective.

\footnotetext{
Affiliations

Department of Neurology, University Hospital Schleswig-Holstein, Kiel, Germany

2 Department of Radiology and Neuroradiology, University Hospital Schleswig-Holstein, Kiel, Germany

3 Department of Neurology, FEK Neumünster, Germany

${ }^{4}$ Department of Neurology, Imland Klinik, Rendsburg, Germany

Department of Neurology, Klinikum Itzehoe, Germany

6 Department of Internal Medicine, Klinik Preetz, Germany

Department of Neurology, DRK Kliniken Berlin, Berlin, Germany

8 Department of Neurology, Helios Klinik, Schleswig, Germany
} 


\section{References}

1 Riedel CH, Zimmermann P, Jensen-Kondering $U$ et al. The importance of size: successful recanalization by intravenous thrombolysis in acute anterior stroke depends on thrombus length. Stroke 2011; 42: 17751777. DOI: STROKEAHA. 110.609693

2 Riedel CH, Jensen $U$, Rohr A et al. Assessment of thrombus in acute middle cerebral artery occlusion using thin-slice nonenhanced Computed Tomography reconstructions. Stroke; a journal of cerebral circulation 2010; 41: 1659-1664. DOI: 10.1161/STROKEAHA.110.580662

3 European Stroke Organisation Executive C, Committee ESOW. Guidelines for management of ischaemic stroke and transient ischaemic attack 2008. Cerebrovascular diseases (Basel, Switzerland) 2008; 25: 457-507. DOI: 10.1159/000131083

4 Puetz V, Dzialowski I, Hill MD et al. Intracranial thrombus extent predicts clinical outcome, final infarct size and hemorrhagic transformation in ischemic stroke: the clot burden score. International journal of stroke: official journal of the International Stroke Society 2008; 3: 230 - 236. DOI: 10.1111/j.1747-4949.2008.00221.x

5 Smith WS, Sung G, Saver J et al. Mechanical thrombectomy for acute ischemic stroke: final results of the Multi MERCI trial. Stroke; a journal of cerebral circulation 2008; 39: 1205-1212. DOI: 10.1161/STROKEAHA.107.497115

6 Nogueira RG, Lutsep HL, Gupta R et al. Trevo versus Merci retrievers for thrombectomy revascularisation of large vessel occlusions in acute ischaemic stroke (TREVO 2): a randomised trial. Lancet 2012; 380 : 1231 - 1240. DOI: 10.1016/S0140-6736(12)61299-9

7 Broderick JP, Palesch YY, Demchuk AM et al. Endovascular therapy after intravenous t-PA versus t-PA alone for stroke. N Engl J Med 2013; 368 : 893 - 903. DOI: 10.1056/NEJMoa1214300

8 Kidwell CS, Jahan R, Gornbein J et al. A trial of imaging selection and endovascular treatment for ischemic stroke. N Engl J Med 2013; 368: 914-923. DOI: 10.1056/NEJMoa1212793

9 Berkhemer OA, Fransen PS, Beumer D et al. A Randomized Trial of Intraarterial Treatment for Acute Ischemic Stroke. N Engl J Med 2014; DOI: $10.1056 /$ NEJMoa 1411587

10 Investigators PPST. The penumbra pivotal stroke trial: safety and effectiveness of a new generation of mechanical devices for clot removal in intracranial large vessel occlusive disease. Stroke; a journal of cerebral circulation 2009; 40: $2761-2768$. DOI: 10.1161/STROKEAHA.108.544957

11 Castano C, Dorado L, Guerrero C et al. Mechanical thrombectomy with the Solitaire $A B$ device in large artery occlusions of the anterior circulation: a pilot study. Stroke; a journal of cerebral circulation 2010; 41: 1836 - 1840. DOI: 10.1161/STROKEAHA.110.584904

12 Dorn F, Stehle S, Lockau H et al. Endovascular treatment of acute intracerebral artery occlusions with the solitaire stent: single-centre experience with 108 recanalization procedures. Cerebrovascular diseases (Basel, Switzerland) 2012; 34: 70 - 77. DOI: 10.1159/000338903
13 Rohde S, Haehnel S, Herweh C et al. Mechanical thrombectomy in acute embolic stroke: preliminary results with the revive device. Stroke; a journal of cerebral circulation 2011; 42: 2954-2956. DOI: 10.1161/ STROKEAHA.111.616763

14 Mendonca N, Flores A, Pagola J et al. Trevo versus solitaire a head-tohead comparison between two heavy weights of clot retrieval. Journal of neuroimaging: official journal of the American Society of Neuroimaging 2012; 24: 167-170. DOI: 10.1111/j.1552-6569.2012.00730.x

15 Jansen O, Macho JM, Killer-Oberpfalzer M et al. Neurothrombectomy for the Treatment of Acute Ischemic Stroke: Results from the TREVO Study. Cerebrovascular diseases (Basel, Switzerland) 2013; 36: 218-225. DOI: $10.1159 / 000353990$

16 Pagola J, Rubiera M, Flores A et al. Selecting Endovascular Treatment Strategy according to the Location of Intracranial Occlusion in Acute Stroke. Cerebrovascular diseases (Basel, Switzerland) 2013; 35: 502 506. DOI: $10.1159 / 000350198$

17 Ciccone A, Valvassori L, Nichelatti $M$ et al. Endovascular treatment for acute ischemic stroke. N Engl J Med 2013; 368: 904-913. DOI: 10.1056/NEJMoa1213701

18 Leker RR, Eichel R, Gomori JM et al. Stent-based thrombectomy versus intravenous tissue plasminogen activator in patients with acute middle cerebral artery occlusion. Stroke; a journal of cerebral circulation 2012; 43: 3389-3391. DOI: 10.1161/STROKEAHA.112.673665

19 Cohen JE, Rabinstein AA, Ramirez-de-Noriega $F$ et al. Excellent rates of recanalization and good functional outcome after stent-based thrombectomy for acute middle cerebral artery occlusion. Is it time for a paradigm shift? Journal of clinical neuroscience: official journal of the Neurosurgical Society of Australasia 2013; DOI: 10.1016/j. jocn.2012.11.011

20 Bae GS, Kwon HJ, Kang CW et al. Mechanical thrombectomy using a solitaire stent in acute ischemic stroke; initial experience in 40 patients. Journal of cerebrovascular and endovascular neurosurgery 2012; 14: 164-169. DOI: 10.7461/jcen.2012.14.3.164

21 Cohen JE, Gomori JM, Leker RR et al. Recanalization with stent-based mechanical thrombectomy in anterior circulation major ischemic stroke. Journal of clinical neuroscience: official journal of the Neurosurgical Society of Australasia 2012; 19: 39-43. DOI: 10.1016/ j.jocn.2011.06.015

22 Saver JL, Jahan R, Levy EI et al. Solitaire flow restoration device versus the Merci Retriever in patients with acute ischaemic stroke (SWIFT): a randomised, parallel-group, non-inferiority trial. Lancet 2012; 380: 1241 - 1249. DOI: $10.1016 /$ S0140-6736(12)61384-1

23 Stampfl S, Hartmann M, Ringleb PA et al. Stent placement for flow restoration in acute ischemic stroke: a single-center experience with the Solitaire stent system. AJNR American journal of neuroradiology 2011; 32: 1245 -1248. DOI: 10.3174/ajnr.A2505 